\title{
Does fear extinction in the laboratory predict outcomes of exposure therapy? A treatment analog study
}

\author{
Eduard Forcadell ${ }^{\mathrm{a}, \mathrm{b}}$, David Torrents-Rodas ${ }^{\mathrm{a}, \mathrm{c}}$, Bram Vervliet ${ }^{\mathrm{d}, \mathrm{e}}$, David Leiva ${ }^{\mathrm{f}}$, \\ Miquel Tortella-Feliu $^{\mathrm{g}}$, Miquel A. Fullana ${ }^{\text {a,h* }}$
}

a . Department of Psychiatry and Forensic Medicine, School of Medicine, Universitat Autònoma de Barcelona, Bellaterra, Catalonia, Spain;

b. Mental Health Department. Parc Taulí Hospital Universitari. Institut d'Investigació i Innovació Parc Taulí I3PT. Universitat Autònoma de Barcelona. Sabadell, Spain;

c. Specialized Department in Mental Health and Intellectual Disability, Institut Assistència Sanitària (IAS), Parc Hospitalari Martí i Julià, Salt, Catalonia, Spain.

${ }^{\mathrm{d}}$. Center for Excellence on Generalization in Health and Psychopathology, KU Leuven, Leuven, Belgium.

e. Department of Psychiatry, Harvard Medical School, Boston, US \& Department of Psychiatry, Massachusetts General Hospital, Boston, US.

${ }^{\mathrm{f}}$. Department of Social Psychology and Quantitative Psychology, School of Psychology, Universitat de Barcelona, Barcelona, Spain.

${ }^{g}$. University Research Institute on Health Sciencies (IUNICS), Universitat de les Illes Balears, Mallorca, Spain \& PROMOSAM Red de Investigación en procesos, mecanismos y tratamientos psicológicos para la promoción de la salud mental.

${ }^{\mathrm{h}}$. Anxiety Unit, Institute of Neuropsychiatry and Addictions, Hospital del Mar, CIBERSAM, Barcelona, Spain \& IMIM (Hospital del Mar Medical Research Institute), Barcelona, Spain.

Running head: DOES FEAR EXTINCTION PREDICT EXPOSURE THERAPY?

\footnotetext{
* Corresponding author: Miquel A.Fullana

Department of Psychiatry and Forensic Medicine, School of Medicine. UAB Campus, 08193, Bellaterra (Cerdanyola del Vallès) Spain. Tel: (+ 34) 9358123 81. Fax: (+ 34) 935811435

E-mail:mafr@copc.com
} 


\begin{abstract}
Fear extinction models have a key role in our understanding of anxiety disorders and their treatment with exposure therapy. Here, we tested whether individual differences in fear extinction learning and fear extinction recall in the laboratory were associated with the outcomes of an exposure therapy analog (ETA). Fifty adults with fear of spiders participated in a two-day fear-learning paradigm assessing fear extinction learning and fear extinction recall, and then underwent a brief ETA. Correlational analyses indicated that enhanced extinction learning was associated with better ETA outcome. Our results partially support the idea that individual differences in fear extinction learning may be associated with exposure therapy outcome, but suggest that further research in this area is needed.
\end{abstract}

Key words: fear learning, fear conditioning, extinction learning, extinction recall, exposure therapy, anxiety disorders. 


\section{INTRODUCTION}

Fear learning models are important for our understanding of anxiety disorders and their treatment (Graham \& Milad, 2011; VanElzakker, Kathryn Dahlgren, Caroline Davis, Dubois, \& Shin, 2014). In a typical fear learning experiment, an initially neutral stimulus (conditioned stimulus, CS) elicits a conditioned fear response (CR) and generates a fear memory (conditioning) after being repeatedly paired with an aversive unconditioned stimulus (US). In humans, most fear learning experiments use a differential conditioning paradigm, where one CS (CS+) is followed by the US and another is not (CS-).

After conditioning, if the CS is presented repeatedly without the US, the CR decays and a safety memory is formed (extinction learning). In experiments where conditioning and extinction learning occur in different contexts, if the CS is presented later in the context where extinction learning took place, this extinction memory is expressed again (extinction recall).

Abnormalities in some of these fear-learning processes could characterize anxious individuals in comparison to healthy controls and be a hallmark of anxiety disorders. For example, impaired extinction learning has been observed in individuals with panic disorder or generalized anxiety disorder (Michael, Blechert, Vriends, Margraf, \& Wilhelm, 2007; Otto et al., 2014, Pitman \& Orr, 1986), while impaired extinction recall could characterize individuals with post-traumatic stress disorder (Milad et al., 2008). Several theories have been proposed to explain the association between fear learning and anxiety disorders, including failure to inhibit fear to safety cues (Davis, Falls \& Gewirtz, 2000), deficits in associative learning (Grillon, 2002), stimulus generalization (Mineka \& Zinbarg, 1996), and enhanced conditionability (Orr et al., 2000) (reviewed by Lissek et al., 2005).

Apart from their possible role in the origin of anxiety disorders, fear-learning variables may have also an important role in the treatment of these disorders. In fact, there are 
many similarities between exposure therapy and fear extinction learning. Exposure therapy (one of the central components of cognitive-behavioral therapy -CBT- for anxiety-related disorders) uses extinction learning principles by having the patient repeatedly confront a feared situation (CS) in the absence of danger (US) until fear diminishes (Myers \& Davis, 2007). Moreover, extinction learning models may explain the mechanisms through which exposure therapy acts. For example, according to the inhibitory learning theory the original CS-US association learned during fear conditioning is not erased during fear extinction learning, but rather a new association (that the CS no longer predicts the US) is developed (Craske et al., 2008).

Research on fear extinction has gained momentum in recent years thanks to the exciting possibilities offered by translational research (Kindt, 2014; Milad \& Quirk, 2012; Morrison \& Ressler, 2014). Neuroimaging studies have shown that structural or functional variability in brain areas related to fear extinction is associated with the outcome of exposure therapy/CBT (Bryant et al., 2008; Fullana et al., 2014; Hoexter et al., 2013). Moreover, new pharmacological (Singewald, Schmuckermair, Whittle, Holmes, \& Ressler, 2015) and behavioral (Schiller et al., 2010) approaches have been developed that focus on optimizing fear extinction abilities.

An important assumption from this research is that extinction learning in the laboratory is (almost) equivalent to exposure therapy (Berry, Rosenfield, \& Smits, 2009; Hermans, Craske, Mineka, \& Lovibond, 2006), and that the former should predict the latter (i.e. enhanced extinction learning would be associated with better outcomes from exposure therapy); however, this assumption has rarely been tested. One exception is a recent study by Waters and Pine (2016), who assessed fear conditioning and extinction learning in the laboratory using a differential conditioning paradigm and evaluative ratings (arousal and valence) and skin conductance responses (SCR) as measures of fear in a group of clinically 
anxious children who then underwent CBT. The results showed that, during extinction learning, treatment non-responders did not show a significant decrease in fear (measured with the SCR) compared to responders and healthy controls. Waters and Pine (2016) assessed fear learning psychophysiologically using the SCR, and there is evidence that fear-potentiated startle (FPS) could be a more selective (i.e. less sensitive to declarative knowledge) measure of fear (Hamm \& Weike, 2005; Sevenster, Beckers, \& Kindt, 2014; but see Luck \& Lipp, 2015; Purkis \& Lipp, 2001). Moreover, this study did not assess fear extinction recall, which may also be associated with exposure therapy outcomes (Milad \& Quirk, 2012). Finally, it is not clear whether these findings can be replicated in adults, which is important because translational evidence suggests that extinction learning capacities may change over the life span (Baker, Bisby, \& Richardson, 2016; Pattwell et al., 2012).

Another recent study by Ball, Knapp, Paulus, \& Stein (2016) explored the link between extinction learning and exposure therapy in a sample of 24 adults with public speaking anxiety. Brain activation and subjective ratings were assessed during extinction learning, and self-reported anxiety changes were collected during a massed exposure session, mimicking exposure therapy. Results showed that those with better extinction learning and changes in activation in brain regions associated with fear extinction (ventromedial prefrontal cortex, amygdala, insula, and periaqueductal gray) reported greater anxiety reduction during exposure therapy. This study focused only on extinction learning and did not assess extinction recall. Moreover, Ball et al. (2016) did not use psychophysiological measures of fear learning or anxiety reduction.

In the present study, we used a differential conditioning paradigm in adults with fear of spiders to test the hypothesis that individual differences in fear extinction in the laboratory would be associated with the outcome of an analog of exposure therapy (exposure therapy analog, ETA). Specifically, we expected that an enhanced fear extinction learning and fear 
extinction recall would be associated with a greater fear reduction from pre- to post-ETA.

Following previous research (e.g. Pineles et al., 2016; Rabinak et al., 2013), we

operationalized fear extinction as the difference between the CS+ and CS- during extinction learning and extinction recall.

\section{MATERIALS AND METHODS}

See Figure 1 for a summary of the experimental design.

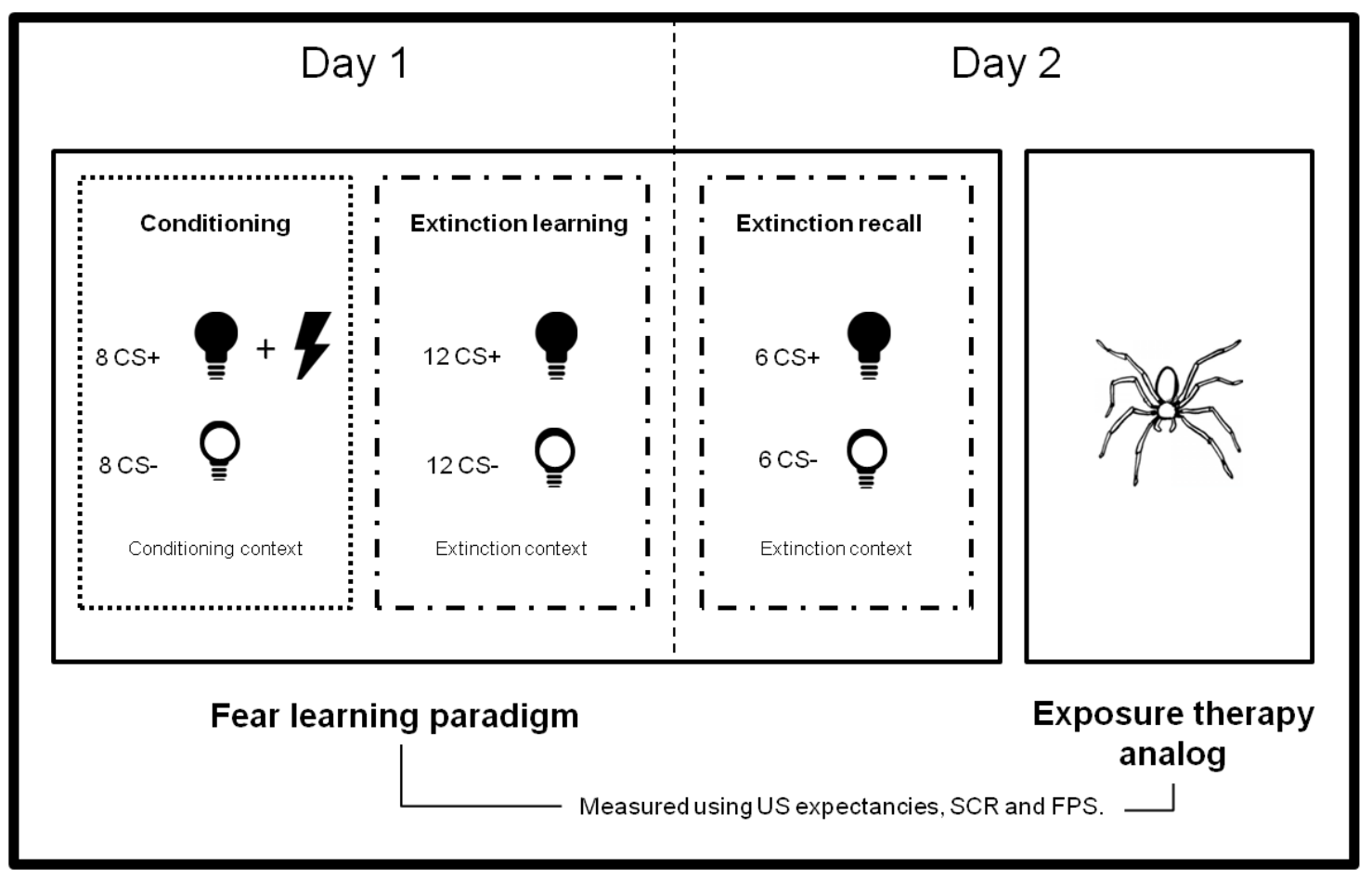

Fig. 1. Summary of experimental design.

US: Unconditioned stimulus; SCR: Skin Conductance Response; FPS: Fear-Potentiated startle; CS+, Conditioned stimulus associated with the unconditioned stimulus during the conditioning phase; CS-, Conditioned stimulus never associated with the unconditioned stimulus.

\section{Participants}

We selected individuals with moderate to strong fear of spiders, as assessed by a dimensional instrument. Participants were recruited by advertisements to participate in a study on "physiological responses to anxiety". Initially, 1504 individuals were screened with the validated Spanish version (Forcadell, Torrents-Rodas, Martinez, Torrubia, \& Fullana, 2014) 
of the Fear of Spiders Questionnaire (FSQ; Szymanski \& O'Donohue, 1995) via a secure web system. Participants who scored in the top quartile of the study distribution (FSQ $\geq 33$; $\mathrm{n}=386$ ) were invited to participate. Of those, 92 accepted to be interviewed by a doctorallevel clinical psychologist using the Mini International Neuropsychiatric Interview (MINI; Sheehan et al., 1998).

Exclusion criteria were: (a) current or lifetime history of mental disorders other than specific phobia (animal type, spiders), as determined by the MINI, supplemented with the specific phobia section of the Structured Clinical Interview for DSM (SCID; First, Spitzer, Gibbon, \& Williams, 2002); (b) use of medication/illicit drugs or medical problems that could interfere with study performance or interpretation; (c) alcohol abuse; (d) pregnancy; (e) not being Spanish-speaker. Female participants had regular menstrual cycles (self-report), had not used oral contraceptives or hormone replacement therapy during the previous three months, and participated in the study during their early follicular phase (days 3-8 of a 28 to 30-day cycle) to avoid possible confounding by sex hormones in fear extinction (Merz et al., 2012; Milad et al., 2006; Pineles et al., 2016). All participants were tested between 5 and 8 PM.

The final sample consisted of 50 participants with moderate to strong fear of spiders $\left(M_{F S Q}=58.98, \mathrm{SD}=17.94 ; M_{\mathrm{age}}=21.50\right.$ years, $\mathrm{SD}=2.93 ; 25$ women $)$. Participants gave written informed consent to take part in the study, which was approved by the corresponding institution's Clinical Research Ethics Committee. Participants were paid $€ 25$.

\section{Procedure overview}

Participants took part in two experimental sessions on two consecutive days. On day one, they rated their fear of spiders (FSQ pre-ETA score), participated in the first part of the fear learning paradigm (conditioning and extinction learning), and selected the two phobic stimuli 
(two most fearful images from a pre-selected set of 30 spider images; see Supplementary Materials-Methods) that would be used during ETA. On day two they participated in the second part of the fear learning paradigm (extinction recall), underwent ETA, and rated their fear of spiders again (FSQ post-ETA score). Psychophysiological responses were recorded continually during the fear learning paradigm and during ETA (see below).

\section{Fear learning paradigm}

We adapted the paradigm developed by Milad, Orr, Pitman, and Rauch (2005), which allows us to assess conditioning, extinction learning, and extinction recall separately. The original task used SCR as the only measure of conditioned fear, but we added two other measures (US expectancies and FPS) (see Supplementary Materials-Methods). Briefly, the visual contexts were photographs of two different rooms (conditioning context, $\mathrm{CX}+$; extinction context, CX-) containing a lamp that switched on to one of two different colors (blue or yellow), which were the CSs (CS+ and CS-). Contexts and CSs were displayed on a computer monitor in front of the participant. On day 1, a conditioning phase (in $\mathrm{CX}+$ ) was followed by an extinction learning phase (in CX-). During conditioning, the CS+ co-terminated with an electric shock (US). The US was individually adjusted before the experiment (day 1) presenting shocks of gradually increasing intensity until a 'definitely annoying but not painful' shock was selected $\left(M_{\text {shock level }}=4.9\right.$ milliamperes $\left.(\mathrm{mA}), \mathrm{SD}=3.3\right)$. Participants were not instructed about the CS-US contingency. During extinction learning (immediately after conditioning), the CS+ was not followed by the US. The CS- was never followed by the US. The extinction learning phase was divided in two equal parts by a 1-minute pause (early and late extinction learning). Day 2 consisted of an extinction recall phase in CX-. During day 2, the CS+ and the CS- were never followed by the US. The US was not recalibrated during day 2. 
Each trial of the experiment started with presentation of the context for 10, 12 or $14 \mathrm{~s}$. Then the CS was presented (i.e. the lamp switched on) for $8 \mathrm{~s}$, and a startle probe (50 ms duration, $100 \mathrm{~dB}$ ) was delivered $7 \mathrm{~s}$ after CS onset. Between trials, a fixation cross was shown for $1 \mathrm{~s}$. In one third of the trials (noise-alone trials, NA), no CS was presented, and instead the context was present for 8 more seconds; the startle probe was presented at second 7 of this extra time. The inter-probe interval varied between 18, 20, and $22 \mathrm{~s}$. Eight trials of each type (CS+, CS-, and NA) were presented during conditioning, and six trials of each were presented during each of the remaining phases (early and late extinction learning, and extinction recall). SCR, FPS and US expectancy ratings were calculated for each trial type.

The SCR signal was sampled at a rate of $125 \mathrm{~Hz}$. SCR magnitudes were computed in microsiemens $(\mu \mathrm{S})$ as the difference between the maximum SCR value and the value at response onset, occurring 1 to $7 \mathrm{~s}$ after CS onset. Trials in which no response was detected or with a response magnitude of $<0.02 \mu \mathrm{S}$ were considered non-response trials (see Dunsmoor, Mitroff, \& LaBar, 2009), and trials showing interference or excessive baseline activity (1.3\%) were rejected after visual inspection. To normalize the distribution of the SCR data, we applied a square root transformation.

Startle amplitudes were computed in microvolts $(\mu \mathrm{V})$ as the difference between the EMG value at response peak and the average EMG during the $50 \mathrm{~ms}$ preceding the probe. If no response was detected in a given trial, the amplitude was scored as $0 \mu \mathrm{V}$. To be considered a valid response, elevations in the EMG recording had to start between 20 and $100 \mathrm{~ms}$, and their peak had to occur between 20 and $150 \mathrm{~ms}$ after the probe. After visual inspection, trials with excessive noise (3.2\%) were rejected. Raw data were transformed into T-scores to control for differences in reactivity. Scorers of SCR and FPS data were blind to the stimuli presented.

Regarding US expectancy ratings, for each trial participants were told to try to predict 
whether the shock would occur in the following seconds each time the lamps in the rooms turned blue or yellow. They had to answer as quickly as possible by clicking on the scale from 0 (no shock) to 10 (shock) displayed at the bottom of the screen (see Supplementary Materials-Methods for further information).

\section{Fear extinction indices}

Based on previous literature (Garfinkel et al., 2014; Pineles et al., 2016; Rabinak et al., 2013, 2014), we calculated for each participant and for each measure (US expectancies, SCR and FPS) an index expressing the "amount of learning" reflecting differences between CS + and CS- during extinction learning (using early extinction and operationalized as a percentage), and extinction recall (using the first two trials) (see Supplementary Materials Table S1). Since the extinction learning index was calculated as a percentage, higher scores indicated enhanced extinction learning (i.e. less discrimination between CS+ and CS-). Since the extinction recall index was calculated as a simple subtraction it had the opposite interpretation (i.e. lower scores indicated enhanced extinction recall).

\section{Exposure therapy analog (ETA)}

We developed a one-session computer-assisted ETA based on exposure therapy principles (i.e. repeated presentation of phobic stimuli). Single-session exposure therapy (Tsao \& Craske, 2000; Vasey, Harbaugh, Buffington, Jones, \& Fazio, 2012), including computerassisted protocols (Andersson et al., 2009; Dewis et al., 2001; Gilroy et al. 2000; Heading et al., 2001; Müller, Kull, Wilhelm, \& Michael, 2011), are effective for treating specific fears and phobias. Our ETA was very similar to that used by Müller et al. (2011) in a randomized controlled trial, and similar effect sizes in fear reduction (see below) as those obtained by Müller et al. (2011) were also observed in the present study. 
During ETA, participants were presented on a computer screen with the two previously selected phobic images (10 minutes each for a total of 20 minutes) and two neutral images (of a pen and a fork; 2,5 minutes each for a total of 5 minutes; see Supplementary Material-Methods). Neutral and phobic images were interleaved and presented 10 times each. To avoid order effects, participants were randomized into two groups that began with either a phobic or a neutral image. Neutral images were included to confirm that phobic images were subjectively and psychophysiologically more aversive.

Participants received brief psychoeducation in which they were instructed to confront phobic stimuli without using overt (i.e. avoid looking) or covert (i.e. distracting) avoidance behaviors. We assessed SCR, FPS and subjective responses (using a visual analog scale, VAS) during ETA. SCR and FPS responses for each stimulus during ETA were quantified off-line using the same procedures as for the fear learning paradigm, with the exception that for the SCR, due to design constraints, we used the maximum score occurring at 1 to $6 \mathrm{~s}$ (not 1 to $7 \mathrm{~s}$ ) after onset of the stimulus. We obtained 20 SCR scores for the phobic and 20 for the neutral stimuli. Two startle probes were presented at the end of each image, with an interprobe interval of $8,9,10,12$, or $14 \mathrm{~s}$. These two scores were averaged to obtain 20 FPS scores for the phobic and 20 for the neutral stimuli (see Supplementary Materials-Methods for further information).

\section{ETA outcome variables}

We evaluated ETA outcomes using three different measures of fear reduction, where higher scores indicated greater fear reduction:

FSQ: Difference between pre- and post-ETA, as measured by the FSQ.

ABS-Fear reduction: Absolute difference between the first response (average of the first two responses to phobic image 1 and phobic image 2) and the last response (average of 
the last two responses to phobic image 1 and phobic image 2) for VAS, SCR and FPS responses during ETA.

\% Fear reduction: Percentage of fear reduction for VAS, SCR and FPS obtained by dividing the last response during ETA (average of phobic image 1 and phobic image 2) by the first response during ETA (average of phobic image 1 and phobic image 2), multiplied by 100 and then subtracted from $100 \%$.

\section{Statistical analyses}

In preliminary analyses, we tested for differences in responses to phobic and neutral stimuli during ETA using three separate (VAS, SCR, and FPS) repeated-measures t-tests. We also assessed the effectiveness of ETA on fear reduction using four separate (FSQ, VAS, SCR, and FPS) repeated-measures t-tests to compare pre- and post-ETA scores. We report Cohen's $d$ (calculated as the difference between means divided by the standard deviation) as an estimate of effect size for these analyses. We studied the performance of the sample during the fear learning paradigm using repeated-measures ANOVA for each phase (conditioning, extinction learning and extinction recall) and for each measure (US expectancies, SCR and FPS), with CS type (CS+ vs. CS-) and Block as within-subjects factors. We averaged SCR and FPS responses over two consecutive trials of the same type (blocks), and applied Greenhouse-Geisser corrections for main effects and interactions involving repeated measures. We report $\eta_{p}^{2}$ as an estimate of effect size for these analyses.

We used Pearson correlations to test the significance of associations between fear extinction indices and ETA outcome for the whole sample. Following our main hypothesis, we expected our extinction learning index to be positively correlated and our extinction recall index to be negatively correlated with ETA outcome. 
Finally, following recent guidelines for the analyses of fear learning data in humans (Lonsdorf et al., 2017), we repeated our extinction learning analyses using only those participants showing evidence of conditioning (i.e., one participant was excluded for the US expectancies analyses, 23 for SCR, and 21 for FPS). Similarly, we calculated extinction recall only for participants who showed evidence of extinction learning (i.e., five participants were excluded for the US expectancies analyses, 32 for SCR, and 35 for FPS) (see Supplementary Materials for the criteria of "successful" conditioning and extinction learning).

\section{RESULTS}

\section{Preliminary analyses}

As expected, phobic stimuli were more fearful than neutral stimuli, both subjectively $\left(M_{\text {phobic }}\right.$ $\left.=4.37, \mathrm{SD}=2.25 ; M_{\text {neutral }}=.03, \mathrm{SD}=.09 ; t(49)=13.65 ; p<.001 ; d=2.38\right)$ and psychophysiologically $\left[\mathrm{SCR}\left(M_{\text {phobic }}=.47, \mathrm{SD}=.17 ; M_{\text {neutral }}=.29, \mathrm{SD}=.15 ; t(49)=10.59\right.\right.$; $p<.001 ; d=1.12) ; \mathrm{FPS}\left(M_{\text {phobic }}=50.77, \mathrm{SD}=1.89 ; M_{\text {neutral }}=49.32, \mathrm{SD}=1.85 ; t(49)=2.74 ;\right.$ $p=.009 ; d=0.78)]$

ETA was effective in reducing fear (see Figure 2), as indicated by a significant prepost ETA reduction in FSQ $\left(M_{\text {pre }}=46.54, \mathrm{SD}=23.78 ; M_{\text {post }}=40.38, \mathrm{SD}=26.38 ; t(49)=\right.$ $2.70 ; p=.009 ; d=0.25)$ and VAS scores $\left(M_{\text {pre }}=5.76, \mathrm{SD}=2.22 ; M_{\text {post }}=3.30, \mathrm{SD}=2.37\right.$; $t(49)=11.40 ; p<.001 ; d=1.07)$, as well as in $\operatorname{SCR}\left(M_{\text {pre }}=.69, \mathrm{SD}=.20 ; M_{\text {post }}=.37, \mathrm{SD}=\right.$ $.17 ; t(49)=12.16 ; p<.001 ; d=1.72)$ and FPS responses $\left(M_{\text {pre }}=53.15, \mathrm{SD}=6.36, M_{\text {post }}=\right.$ 49.48, $\mathrm{SD}=5.67 ; t(49)=2.71 ; p=.009 ; d=0.61)$.

For all measures (US expectancies, SCR, and FPS) and for the whole sample, we found evidence of successful conditioning (i.e. higher response to the CS+ than to the CS- in the last block of conditioning), as shown by a significant main effect of CS type ( $p$ s $<.001)$ and significant [US expectancies: $F(2.71,130.23)=79.76, p<.001, \eta_{p}^{2}=.62$; SCR: $F(2.87$, 
$\left.136.17)=3.59, p=.021, \eta_{p}^{2}=.07\right]$ or almost significant $($ FPS: $F(2.31,101.48)=2.66, p=$ $\left..072, \eta_{p}^{2}=.06\right)$ CS type $\times$ Block interactions, as well as follow-up analyses indicating larger responses to the $\mathrm{CS}+$ than to the $\mathrm{CS}$ - in the last block of conditioning ( $p$ s $<.001 ; d$ s ranging from 0.62 to 4). For SCR and FPS and for the whole sample there was evidence of successful extinction learning (i.e. similar response to the CS+ and CS- in the last block of extinction), as evidenced by a non-significant CS type main effect and a non-significant CS type $\times$ Block interaction $(p s>.108)$. Analyses of US expectancies for the whole sample revealed a main effect of CS type, $F(1,48)=7.04, p=.011, \eta_{p}^{2}=.128$, but a non-significant CS type $\times$ Block interaction $(p=.080)$. For FPS and for the whole sample, there was evidence of successful extinction recall (i.e. similar response to the CS+ and CS- in the extinction context during the first block of extinction recall), as shown by a non-significant CS type main effect and a nonsignificant CS type $\times$ Block interaction $(p s=.277)$. For US expectancies and SCR we found no evidence of extinction recall for the whole sample [significant CS type $\times$ Block interaction for US expectancies: $F(2,96)=14.77, p<.001, \eta_{p}^{2}=.24$; and for SCR: $F(2,96)=4.92, p=$ $\left..009, \eta_{p}^{2}=.09\right]$ 


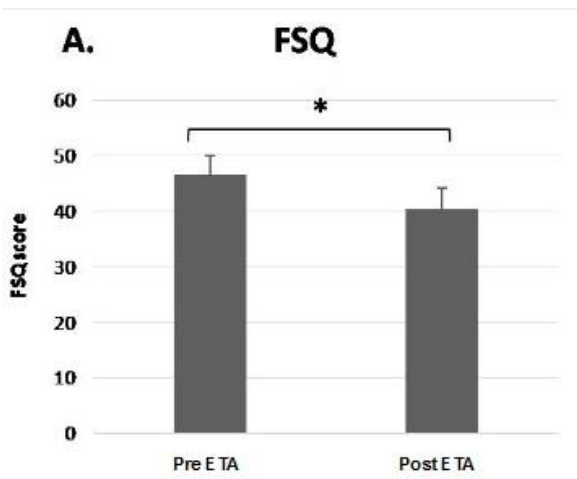

C.

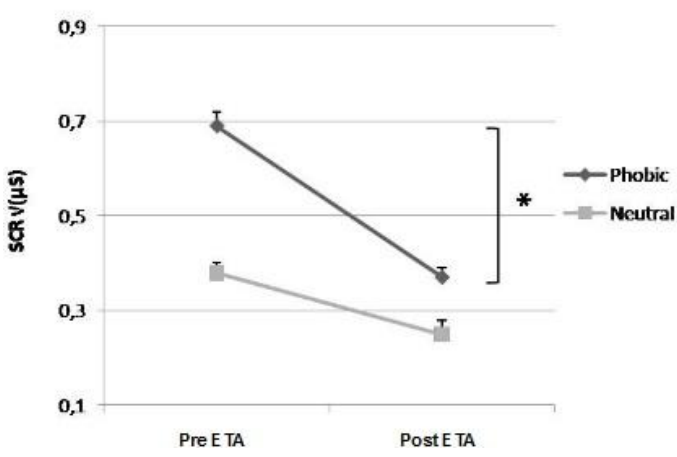

B.

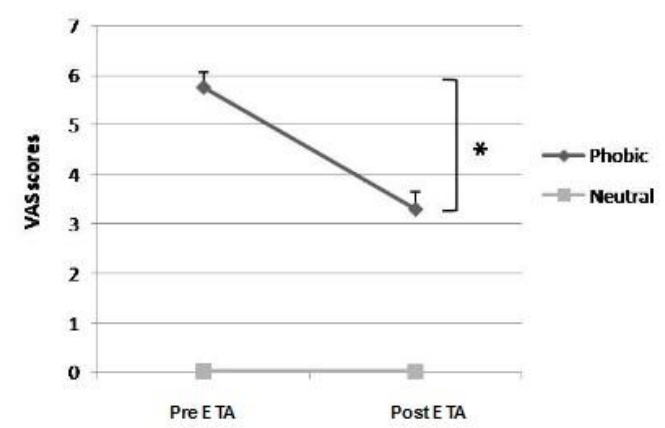

D.

FPS

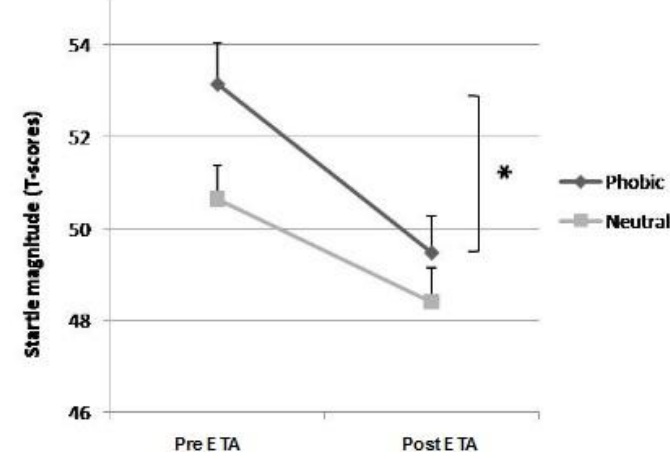

Fig. 2. Effectiveness of ETA (exposure therapy analog) on different outcome measures: (a) Fear of Spiders Questionnaire (FSQ), (b) Visual Analog Scale (VAS), (c) Skin Conductance Response (SCR), and (d) FearPotentiated startle (FPS). Bars represent standard errors of the mean. Asterisks indicate significant differences, * $p<.05$

\section{Fear extinction indices and ETA outcome}

Consistent with our hypothesis, our index of fear extinction learning (as measured with US expectancies) was positively associated with one of our measures of fear reduction (ABSFear reduction), i.e. predicted a greater fear reduction from pre-to post-ETA. The extinction recall index was, however, not significantly associated with ETA outcome (see Table 1). Results did not change when we conducted partial correlations controlling for the intensity of the US (data not shown). 
Table 1. Correlations between fear extinction indices and ETA.

\begin{tabular}{|c|c|c|c|}
\hline & ETA outcome variables & Pearson correlation & $p$ \\
\hline \multicolumn{4}{|c|}{ EXTINCTION LEARNING } \\
\hline \multirow[t]{3}{*}{ US expectancies } & FSQ-Fear reduction & -0.098 & 0.563 \\
\hline & ABS-Fear reduction (VAS) & 0.338 & 0.041 \\
\hline & $\%$ Fear reduction (VAS) & 0.242 & 0.149 \\
\hline \multirow[t]{3}{*}{ SCR } & FSQ-Fear reduction & -0.154 & 0.530 \\
\hline & ABS-Fear reduction (SCR) & -0.096 & 0.697 \\
\hline & $\%$ Fear reduction (SCR) & -0.060 & 0.808 \\
\hline \multirow[t]{3}{*}{ FPS } & FSQ-Fear reduction & 0.256 & 0.250 \\
\hline & ABS-Fear reduction (FPS & 0.039 & 0.863 \\
\hline & $\%$ Fear reduction (FPS & 0.061 & 0.787 \\
\hline \multicolumn{4}{|c|}{ EXTINCTION RECALL } \\
\hline \multirow[t]{3}{*}{ US expectancies } & FSQ-Fear reduction & 0.069 & 0.635 \\
\hline & ABS-Fear reduction (VAS) & 0.276 & 0.052 \\
\hline & $\%$ Fear reduction (VAS) & 0.171 & 0.236 \\
\hline \multirow[t]{3}{*}{ SCR } & FSQ-Fear reduction & -0.002 & 0.988 \\
\hline & ABS-Fear reduction (SCR) & -0.132 & 0.361 \\
\hline & $\%$ Fear reduction $(\mathrm{SCR})$ & -0.100 & 0.503 \\
\hline \multirow[t]{3}{*}{ FPS } & FSQ-Fear reduction & -0.018 & 0.903 \\
\hline & ABS-Fear reduction (FPS) & 0.137 & 0.342 \\
\hline & $\%$ Fear reduction (FPS) & 0.145 & 0.316 \\
\hline
\end{tabular}

ETA: Exposure therapy analog; US: Unconditioned stimulus; SCR: Skin Conductance Response; FPS: Fear-Potentiated startle; VAS: Visual Analog Scale; FSQ: Fear of spiders questionnaire; \% Fear reduction: Percentage of fear reduction; ABS-Fear reduction: Absolute fear reduction. Significant values in bold.

\section{Additional analyses}

We repeated the analyses related to ETA outcome described above excluding individuals who showed no conditioning for the extinction learning analyses, or those who did not show extinction learning for the extinction recall analyses (Table 2). We replicated the significant positive correlation between extinction learning (measured with US expectancies and FPS) and ABS-Fear reduction $(r=.358, p=.032 ; r=.667, p=.013)$ and we also found a significant positive correlation between extinction learning and \% Fear reduction as measured with FPS, $r=.704, p=.007)$. Unexpectedly, in these additional analyses our index of fear extinction recall (as measured with FPS) was positively associated with ABS-Fear reduction $(r=.527, p=.044)$ and $\%$ Fear reduction $(r=.548, p=.035)$ (i.e. those showing less 
extinction recall showed greater fear reduction from pre- to post-ETA). We also repeated our correlational analyses excluding one possible outlier (a participant with a pre-post ETA change score in the FSQ 2 standard deviations above the mean) and our results remained unchanged.

Table 2. Correlations between fear extinction indices and ETA. Results excluding individuals without successful fear conditioning and extinction learning.

\begin{tabular}{|c|c|c|c|}
\hline & ETA outcome variables & Pearson correlation & $p$ \\
\hline \multicolumn{4}{|c|}{ EXTINCTION LEARNING } \\
\hline \multirow[t]{3}{*}{ US expectancies } & FSQ-Fear reduction & -0.111 & 0.521 \\
\hline & ABS-Fear reduction (VAS) & 0.358 & 0.032 \\
\hline & $\%$ Fear reduction (VAS) & 0.266 & 0.117 \\
\hline \multirow[t]{3}{*}{ SCR } & FSQ-Fear reduction & 0.119 & 0.761 \\
\hline & ABS-Fear reduction (SCR) & 0.409 & 0.275 \\
\hline & $\%$ Fear reduction (SCR) & 0.298 & 0.436 \\
\hline \multirow[t]{3}{*}{ FPS } & FSQ-Fear reduction & 0.007 & 0.982 \\
\hline & ABS-Fear reduction (FPS) & 0.667 & 0.013 \\
\hline & $\%$ Fear reduction (FPS) & 0.704 & 0.007 \\
\hline \multicolumn{4}{|c|}{ EXTINCTION RECALL } \\
\hline \multirow[t]{3}{*}{ US expectancies } & FSQ-Fear reduction & 0.023 & 0.883 \\
\hline & ABS-Fear reduction (VAS) & 0.246 & 0.103 \\
\hline & $\%$ Fear reduction (VAS) & 0.151 & 0.323 \\
\hline \multirow[t]{3}{*}{ SCR } & FSQ-Fear reduction & 0.367 & 0.134 \\
\hline & ABS-Fear reduction (SCR) & -0.109 & 0.667 \\
\hline & $\%$ Fear reduction $(\mathrm{SCR})$ & -0.161 & 0.551 \\
\hline \multirow[t]{3}{*}{ FPS } & FSQ-Fear reduction & 0.005 & 0.985 \\
\hline & ABS-Fear reduction (FPS) & 0.527 & 0.044 \\
\hline & $\%$ Fear reduction (FPS) & 0.548 & 0.035 \\
\hline
\end{tabular}

ETA: Exposure therapy analog; US: Unconditioned stimulus; SCR: Skin Conductance Response; FPS: Fear-Potentiated startle; VAS: Visual Analog Scale; FSQ: Fear of spiders questionnaire; \% Fear reduction: Percentage of fear reduction; ABS-Fear reduction: Absolute fear reduction. Significant values in bold.

Finally, since there is a lot of variability in how researchers have operationalized and calculated fear-learning indices, we calculated alternative fear extinction indices (Supplementary Materials-Table S2). We found that two alternative indices of extinction recall (based on Pineles et al., 2016) were positively correlated with ABS-Fear reduction 
(extinction recall: $r=.325, p=.021 ; r=.305, p=.031$ ). When we excluded participants individuals without successful fear conditioning and extinction learning, none of these alternative indices was significantly associated with ETA outcome, except an extinction learning index using SCR (based on Rabinak et al., 2014), which was positively associated with $\%$ fear reduction $(r=.455, p=.022)$.

\section{DISCUSSION}

In this study, we examined the association between fear extinction in the laboratory and the outcomes of an ETA. Our analyses suggest that individual differences in fear extinction may be associated with fear reduction during an ETA, although they seem to diminish previous assumptions about the magnitude of the association between extinction and exposure therapy. We found the expected association and in the expected direction for fear extinction learning, i.e. individuals with higher extinction learning capacity (as assessed by the discrimination between the CS+ and CS-) showed greater fear reduction from pre- to post-ETA. However, these results must be interpreted with caution since they were obtained only for some of our fear measures (US expectancies for the whole sample analyses, and US expectancies and FPS when we excluded individuals without successful fear conditioning and extinction learning).

Our results are partially in agreement with Water and Pine (2016), who found that individual differences in fear extinction learning might moderate response to CBT. However, there are important methodological differences between the studies: we tested healthy individuals in a purely experimental setting and using an analog of exposure therapy, whereas Waters and Pine (2016) tested anxious children in a clinical setting and using a 10-week group-based CBT program. We also used a different fear-learning paradigm. Our results are also consistent with those of Ball et al. (2016), who found that individuals with fear of public speaking and higher extinction learning reported better outcomes during a massed exposure 
therapy session. However, we note some differences here, in that Ball et al. (2016) did not assess fear extinction recall and did not explore psychophysiological variables.

Taken together, these results seem consistent with models that consider extinction learning to be a central process to exposure therapy (e.g. Craske, Liao, \& Vervliet, 2012), and support the predictive validity of the fear extinction model in anxiety disorders (Vervliet \& Raes, 2013). From a clinical perspective, our results indicate that laboratory studies of extinction learning may indeed provide insights into exposure therapy, e.g. by helping to identify patients who will benefit or not from exposure-based therapies, and thereby adapt therapeutic strategies. Moreover, these results support current translational efforts to "boost" fear extinction learning as a way to improve CBT therapeutic outcomes (Fitzgerald, Seemann, \& Maren, 2014; Pittig, van den Berg, \& Vervliet, 2015; Rodrigues et al., 2014). Unexpectedly, in our additional analyses, we found that enhanced extinction recall was associated with a more negative outcome during the ETA. This contrasts with a previous report showing association between enhanced extinction recall and a positive CBT outcome in social anxiety disorder (Berry et al., 2009). However, there are important differences between our experimental measure of extinction recall (focusing on discriminative learning between a CS+ and CS-) and that used by Berry et al. (2009), which focused on betweensession fear reduction. Moreover, in previous experimental fear-learning studies, the operationalization of extinction recall has varied a lot, and it is possible that the different ways of measuring the process affect its association with other variables. Notably, when we used alternative indices of extinction recall, the direction of the association (greater extinction recall $=$ more negative outcome) remained the same. A previous study in patients with obsessive-compulsive disorder (OCD) (Milad et al., 2013) found that OCD severity was positively correlated with extinction recall (i.e. better extinction recall was associated with 
higher severity), which is also counterintuitive. Therefore, clarifying the association between fear extinction recall and therapy outcome is an important topic for future research.

The finding that extinction learning has a different predictive capacity than extinction recall is consistent with neurobiological studies showing that these two processes are independent (Milad et al., 2007; Phelps, Delgado, Nearing, \& Ledoux, 2004; Quirk \& Mueller, 2008). Moreover, from a methodological perspective, the fact that extinction learning may predict ETA outcomes could make the assessment of extinction recall redundant. This is important because of the time cost of separate experimental sessions to assess extinction recall.

Furthermore, some measures in our study (e.g. US expectancies) had a better predictive value than others (e.g. SCR). This is consistent with many previous fear-learning studies reporting a dissociation between fear measures (e.g. Sevenster et al. 2014). Importantly, our US expectancies-based indices remained the most robustly associated with our ETA, which supports the use of US expectancies as measures of fear extinction with clinical relevance (Boddez et al., 2013). Although this has important practical implications because US ratings are easier to collect than psychophysiological measures, caution is warranted since such association was found for only one of the three ETA outcomes tested.

In this study we used an "analog" sample, which is consistent with new initiatives in mental health research that focus on domains or constructs across a dimension of function rather than on clinical diagnoses (Haro et al., 2014; Insel et al., 2010). Previous research on the use of D-cycloserine as an "extinction enhancer" in phobic fears has produced contradictory results in clinical (where positive results have been achieved, e.g. Ressler et al., 2004) and analog (where mostly negative results have been achieved, e.g. Guastella, Dadds, Lovibond, Mitchell, \& Richardson, 2007) samples. When interpreting this contradiction, Grillon (2009) has proposed a "dual-model theory" of fear learning, according to which two 
systems would be involved in fear learning in humans: a higher-order cognitive system (associated with the conscious awareness of danger) and an "automatic" lower-order system (independent of conscious awareness processes, and where D-cycloserine would act on). Lower-order processes could play a more important role in clinical than in analog phobic samples. Although exposure therapy probably taps into both higher order and lower order mechanisms (see Grillon, 2009), it is possible that some of our negative findings on the association between extinction measures and fear reduction measures depend on the use of an analog rather than a clinical sample. In a similar way, this could explain why our "higher order measures" (i.e. risk ratings) were a better predictor of fear reduction that our "lower order measures" (i.e. FPS).

Our study has several strengths. We measured fear learning using a well-established paradigm with three different fear measures, while controlling for variables that are known to affect fear learning (menstrual cycle, time of the day). Moreover, our recruitment strategy avoided typical factors that confound fear learning experiments in anxious individuals (comorbidity, medication).

In addition, we note various limitations. First, our sample was relatively small for some of the analyses, but is still much larger $(n=50$ versus $n=24)$ than that used in a previous study on the association between fear extinction and exposure therapy (Ball et al. 2016).We computed post-hoc power (two-tailed) for our significant bivariate correlations using the sample size, the effect size, and the alpha error (.05). We had $68 \%$ power to detect a significant correlation between extinction learning and ETA (one-tailed 79\%), and 59\% to $82 \%$ (one-tailed from $71 \%$ to $90 \%$ ) for the other additional significant correlations. Thus, we had only moderate true power to accept our hypothesis. Second, in the paradigm employed here, conditioning and extinction learning occurred consecutively with no time for longer consolidation of fear conditioning. Third, our ETA was much shorter than the average 
exposure therapy "in the clinic". Our ETA cannot therefore be equated with exposure therapy, but rather as a model of exposure therapy that focuses on exposure principles. However, our data support a significant reduction in fear, and previous research has shown a significant fear reduction with similar "doses" of exposure therapy (e.g. Ball et al., 2016; Kleim et al., 2014; Müller et al., 2011). Single-day exposures have been proposed as a laboratory analog for clinical exposure therapy (Tsao \& Craske, 2000). Importantly, there was sufficient variability in our ETA outcomes to examine individual differences. Fourth, fear of spiders involves also disgust, not only fear (Cisler, Olatunji, \& Lohr, 2009). Although exposure-based treatments are effective in reducing spider fear (Olatunji, Huijding, De Jong, $\&$ Smits, 2011), it is unclear whether our results would replicate in other phobic fears. Finally, we did not conduct a follow-up study, and thus were unable to test whether these associations would remain significant over time. This is especially important for processes such as extinction recall.

Notwithstanding these limitations, we have shown that fear extinction learning assessed in the laboratory is associated with the outcome of an ETA. These data may help to confirm that extinction learning is a valid pre-clinical model of exposure therapy and support current efforts to improve therapeutic outcomes by focusing on this process. Clarifying the role of other fear-learning processes (i.e., extinction recall) in the prediction of exposurebased interventions awaits further research. 


\section{REFERENCES}

Andersson, G., Waara, J., Jonsson, U., Malmaeus, F., Carlbring, P., \& Öst, L. (2009). Internet-based self-help versus one-session exposure in the treatment of spider phobia: a randomized controlled trial. Cognitive Behaviour Therapy, 38(2), 114-120. doi: $10.1080 / 16506070902931326$

Baker, K. D., Bisby, M. A., \& Richardson, R. (2016). Impaired fear extinction in adolescent rodents: Behavioural and neural analyses. Neuroscience and Biobehavioral Reviews,70, 59-73. doi: 10.1016/j.neubiorev.2016.05.019

Ball, T. M., Knapp, S. E., Paulus, M. P., \& Stein, M. B. (2016). Brain activation during fear extinction predicts exposure success. Depression and Anxiety, 34(3), 257-266. doi: 10.1002/da.22583

Berry, A. C., Rosenfield, D., \& Smits, J. A. J. (2009). Extinction retention predicts improvement in social anxiety symptoms following exposure therapy. Depression and Anxiety, 26(1), 22-27. doi: 10.1002/da.20511

Boddez, Y., Baeyens, F., Luyten, L., Vansteenwegen, D., Hermans, D., \& Beckers, T. (2013). Rating data are underrated: Validity of US expectancy in human fear conditioning. Journal of Behavior Therapy and Experimental Psychiatry, 44(2), 201-206. doi: 10.1016/j.jbtep.2012.08.003

Bryant, R. A., Felmingham, K., Whitford, T. J., Kemp, A., Hughes, G., Peduto, A., \& Williams, L. M. (2008). Rostral anterior cingulate volume predicts treatment response to cognitive-behavioural therapy for posttraumatic stress disorder. Journal of Psychiatry \& Neuroscience, 33(2), 142-146. doi: 10.1017/S0033291707002231

Cisler, J. M., Olatunji, B. O., \& Lohr, J. M. (2009). Disgust, fear, and the anxiety disorders: A critical review. Clinical Psychology Review, 29(1), 34-46. doi: 10.1016/j.cpr.2008.09.007 
Craske, M. G., Kircanski, K., Zelikowsky, M., Mystkowski, J., Chowdhury, N., \& Baker, A. (2008). Optimizing inhibitory learning during exposure therapy. Behaviour Research and Therapy, 46(1), 5-27. doi: 10.1016/j.brat.2007.10.003

Craske, M., Liao, B., \& Vervliet, B. (2012). Role of inhibition in exposure therapy. Journal of Experimental Psychopathology, 3(3), 322-345. doi: 10.5127/jep.026511

Davis, M., Falls, W. A., \& Gewirtz, J. (2000). Neural Systems Involved in Fear Inhibition: Extinction and Conditioned Inhibition. In Contemporary issues in modeling psychopathology (pp. 113-141). doi: 10.1007/978-1-4757-4860-4_8

Dewis, L. M., Kirkby, K. C., Martin, F., Daniels, B. A., Gilroy, L. J., \& Menzies, R. G. (2001). Computer-aided vicarious exposure versus live graded exposure for spider phobia in children. Journal of Behavior Therapy and Experimental Psychiatry, 32(1), 17-27. doi: 10.1016/S0005-7916(01)00019-2

Dunsmoor, J. E., Mitroff, S. R., \& LaBar, K. S. (2009). Generalization of conditioned fear along a dimension of increasing fear intensity. Learning \& Memory, 16(7), 460-469. doi: $10.1101 / \mathrm{lm} .1431609$

First, M.B., Spitzer, R. L., Gibbon, M., Williams, J. B. W. (2002). Structured Clinical Interview for DSM-IV-TR Axis I Disorders, Research Version, Non-patient Edition (SCID-I/NP). New York, NY: Biometrics Research, New York State Psychiatric Institute.

Fitzgerald, P. J., Seemann, J. R., \& Maren, S. (2014). Can fear extinction be enhanced? A review of pharmacological and behavioral findings. Brain Research Bulletin, 105, 4660. doi: 10.1016/j.brainresbull.2013.12.007

Forcadell, E., Torrents-Rodas, D., Martinez, E., Torrubia, R., \& Fullana, M. A. (2014). Reliability and validity of the Spanish version of the Fear of Spiders Questionnaire. Poster presented at the meeting of VII Congreso Internacional y XII Nacional de 
Psicologia clínica, Seville, Spain.

Fullana, M. A., Cardoner, N., Alonso, P., Subirà, M., López-Solà, C., Pujol, J., ... SorianoMas, C. (2014). Brain regions related to fear extinction in obsessive-compulsive disorder and its relation to exposure therapy outcome: A morphometric study. Psychological Medicine, 44(4), 845-856. doi: 10.1017/s0033291713001128

Garfinkel, S. N., Abelson, J. L., King, A. P., Sripada, R. K., Wang, X., Gaines, L. M., \& Liberzon, I. (2014). Impaired contextual modulation of memories in PTSD: an fMRI and psychophysiological study of extinction retention and fear renewal. Journal of Neuroscience, 34(40), 13435-13443. doi: 10.1523/JNEUROSCI.4287-13.2014

Gilroy, L., Kirkby, K., Daniels, B., Menzies, R., \& Montgomery, I. (2000). Controlled comparison of computer-aided vicarious exposure versus live exposure in the treatment of spider phobia. Behavior Therapy, 31(4), 733-744. doi:10.1016/S00057894(00)80041-6

Graham, B. M., \& Milad, M. R. (2011). The study of fear extinction: Implications for anxiety disorders. American Journal of Psychiatry, 168(12), 1255-1265. doi:

10.1176/appi.ajp.2011.11040557

Grillon, C. (2002). Associative learning deficits increase symptoms of anxiety in humans. Biological Psychiatry, 51(11), 851-858. doi: 10.1016/S0006-3223(01)01370-1

Grillon, C. (2009). D-Cycloserine facilitation of fear extinction and exposure-based therapy might rely on lower-level, automatic mechanisms. Biological Psychiatry, 66(7), 636641. doi: 10.1016/j.biopsych.2009.04.017

Guastella, A.J., Dadds, M.R., Lovibond, P.F., Mitchell, P., \& Richardson, R. (2007). A randomized controlled trial of the effect of d-cycloserine on exposure therapy for spider fear. Journal of Psychiatric Research, 41(6), 466-471. doi:

10.1016/j.jpsychires.2006.05.006 
Hamm, A. O., \& Weike, A. I. (2005). The neuropsychology of fear learning and fear regulation. International Journal of Psychophysiology, 57(1), 5-14. doi: 10.1016/j.ijpsycho.2005.01.006

Haro, J. M., Ayuso-mateos, J. L., Bitter, I., Demotes-mainard, J., Leboyer, M., Lewis, S. W., ... Walker-Tilly, T. (2014). ROAMER : roadmap for mental health research in Europe. International Journal of Methods in Psychiatric Research, 23(1), 1-14. doi: $10.1002 / \mathrm{mpr}$

Heading, K., Kirkby, K. C., Martin, F., Daniels, B., Gilroy, L., \& Menzies, R. (2001). Controlled comparison of single-session treatments for spider phobia: live graded exposure alone versus computer-aided vicarious exposure. Behaviour Change, 18(2), 103-113. doi:10.1375/bech.18.2.103

Hermans, D., Craske, M. G., Mineka, S., \& Lovibond, P. F. (2006). Extinction in human fear conditioning. Biological Psychiatry, 60(4), 361-368. doi: 10.1016/j.biopsych.2005.10.006

Hoexter, M. Q., Dougherty, D. D., Shavitt, R. G., D’Alcante, C. C., Duran, F. L. S., Lopes, A. C., ... Miguel, E. C. (2013). Differential prefrontal gray matter correlates of treatment response to fluoxetine or cognitive-behavioral therapy in obsessivecompulsive disorder. European Neuropsychopharmacology, 23(7), 569-580. doi: 10.1016/j.euroneuro.2012.06.014

Insel, T., Cuthbert, B., Garvey, M., Heinssen, R., Pine, D. S., Quinn, K., ... Wang, P. (2010). Research domain criteria (RDoC): toward a new classification framework for research on mental disorders. The American Journal of Psychiatry, 167(7), 748-751. doi: 10.1176/appi.ajp.2010.09091379

Kindt, M. (2014). A behavioural neuroscience perspective on the aetiology and treatment of anxiety disorders. Behaviour Research and Therapy, 62, 24-36. doi: 
10.1016/j.brat.2014.08.012

Kleim, B., Wilhelm, F.H., Temp, L., Margraf, J., Wiederhold, B.K., \& Rasch, B. (2014). Sleep enhances exposure therapy. Psychological Medicine, 44(7), 1511-1519. doi: $10.1017 / \mathrm{S} 0033291713001748$

Lissek, S., Powers, A. S., McClure, E. B., Phelps, E. A., Woldehawariat, G., Grillon, C., \& Pine, D. S. (2005). Classical fear conditioning in the anxiety disorders: A meta-analysis. Behaviour Research and Therapy, 43(11), 1391-1424. doi: 10.1016/j.brat.2004.10.007

Lonsdorf, T., Menz, M., Andreatta, M., Fullana, M.A., Golkar, A., Haaker, J., Heitland, I., Hermann, A., Kuhn, M., Kruse, O., Meir Drexler, S., Meulders, A., Nees, F., Pittig, A., Richter, J., Römer, S., Shiban, Y., Schmitz, A., Straube, B., Vervliet, B., Wendt, J., Baas, J. and Merz, C. (2017). Don’t fear 'fear conditioning': Methodological considerations for the design and analysis of studies on human fear acquisition, extinction, and return of fear. Neuroscience \& Biobehavioral Reviews, 77, 247-285. doi: 10.1016/j.neubiorev.2017.02.026

Luck, C., \& Lipp, O. (2015). A potential pathway to the relapse of fear? Conditioned negative stimulus evaluation (but not physiological responding) resists instructed extinction. Behaviour Research And Therapy, 66, 18-31. doi: 10.1016/j.brat.2015.01.001

Merz, C. J., Tabbert, K., Schweckendiek, J., Klucken, T., Vaitl, D., Stark, R., \& Wolf, O. T. (2012). Oral contraceptive usage alters the effects of cortisol on implicit fear learning. Hormones and Behavior, 62(4), 531-538. doi: 10.1016/j.yhbeh.2012.09.001

Michael, T., Blechert, J., Vriends, N., Margraf, J., \& Wilhelm, F. H. (2007). Fear conditioning in panic disorder: Enhanced resistance to extinction. Journal of Abnormal Psychology, 116(3), 612-617. doi: 10.1037/0021-843X.116.3.612

Milad, M. R., Furtak, S. C., Greenberg, J. L., Keshaviah, A., Im, J. J., Falkenstein, M. J., ... Wilhelm, S. (2013). Deficits in conditioned fear extinction in obsessive-compulsive 
disorder and neurobiological changes in the fear circuit. Journal of the American Medical Association Psychiatry, 70(6), 608-618. doi: 10.1001/jamapsychiatry.2013.914

Milad, M. R., Goldstein, J. M., Orr, S. P., Wedig, M. M., Klibanski, A., Pitman, R. K., \& Rauch, S. L. (2006). Fear conditioning and extinction: Influence of sex and menstrual cycle in healthy humans. Behavioral Neuroscience, 120(6), 1196-1203. doi: 10.1037/0735-7044.120.5.1196

Milad, M. R., Orr, S. P., Lasko, N. B., Chang, Y., Rauch, S. L., \& Pitman, R. K. (2008). Presence and acquired origin of reduced recall for fear extinction in PTSD: Results of a twin study. Journal of Psychiatric Research, 42(7), 515-520. doi: 10.1016/j.jpsychires.2008.01.017

Milad, M. R., Orr, S. P., Pitman, R. K., \& Rauch, S. L. (2005). Context modulation of memory for fear extinction in humans. Psychophysiology, 42(4), 456-464. doi:10.1111/j.1469-8986.2005.00302.x

Milad, M. R., \& Quirk, G. J. (2012). Fear extinction as a model for translational neuroscience: Ten years of progress. Annual Review of Psychology, 63(1), 129-151. doi: 10.1146/annurev.psych.121208.131631

Milad, M. R., Wright, C. I., Orr, S. P., Pitman, R. K., Quirk, G. J., \& Rauch, S. L. (2007). Recall of fear extinction in humans activates the ventromedial prefrontal cortex and hippocampus in concert. Biological Psychiatry, 62(5), 446-454. doi: 10.1016/j.biopsych.2006.10.011

Mineka, S., \& Zinbarg, R. (1996). Conditioning and ethological models of anxiety disorders: Stress-in-Dynamic-Context Anxiety models. In Nebraska Symposium on Motivation, 1995: Perspectives on anxiety, panic, and fear. (pp. 135-210).

Morrison, F. G., \& Ressler, K. J. (2014). From the neurobiology of extinction to improved clinical treatments. Depression and Anxiety, 31(4), 279-290. doi: 10.1002/da.22214 
Myers, K. M., \& Davis, M. (2007). Mechanisms of fear extinction. Molecular Psychiatry, 12(2), 120-150. doi:10.1038/sj.mp.4001939

Müller, B. H., Kull, S., Wilhelm, F. H., \& Michael, T. (2011). One-session computer-based exposure treatment for spider-fearful individuals - Efficacy of a minimal self-help intervention in a randomised controlled trial. Journal of Behavior Therapy and Experimental Psychiatry, 42(2), 179-184. doi: 10.1016/j.jbtep.2010.12.001

Olatunji, B. O., Huijding, J., De Jong, P. J., \& Smits, J. A. J. (2011). The relative contributions of fear and disgust reductions to improvements in spider phobia following exposure-based treatment. Journal of Behavior Therapy and Experimental Psychiatry, 42(1), 117-121. doi: 10.1016/j.jbtep.2010.07.007

Orr, S. P., Metzger, L. J., Lasko, N. B., Macklin, M. L., Peri, T., \& Pitman, R. K. (2000). De novo conditioning in trauma-exposed individuals with and without posttraumatic stress disorder. Journal of Abnormal Psychology, 109(2), 290-298. doi: 10.1037/0021843X.109.2.290

Otto, M. W., Moshier, S. J., Kinner, D. G., Simon, N. M., Pollack, M. H., \& Orr, S. P. (2014). De novo fear conditioning across diagnostic groups in the affective disorders: Evidence for learning impairments. Behavior Therapy, 45(5), 619-629. doi: 10.1016/j.beth.2013.12.012

Pattwell, S. S., Duhoux, S., Hartley, C. a, Johnson, D. C., Jing, D., \& Elliott, M. D. (2012). Altered fear learning across development in both mouse and human. Proceedings of the National Academy of Sciences, 109(40), 16318-16323. doi: 10.1073/pnas.1206834109

Phelps, E. A., Delgado, M. R., Nearing, K. I., \& Ledoux, J. E. (2004). Extinction learning in humans: Role of the amygdala and vmPFC. Neuron, 43(6), 897-905. doi: 10.1016/j.neuron.2004.08.042

Pineles, S. L., Nillni, Y. I., King, M. W., Patton, S. C., Bauer, M. R., Mostoufi, S. M., ... Orr, 
S. P. (2016). Extinction retention and the menstrual cycle: Different associations for women with posttraumatic stress disorder. Journal of Abnormal Psychology, 125(3), 349-355. doi: 10.1037/abn0000138

Pitman, R. K., \& Orr, S. P. (1986).Test of the conditioning model of neurosis: Differential aversive conditioning of angry and neutral facial expressions in anxiety disorder patients. Journal of Abnormal Psychology, 95(3), 208-213.

Pittig, A., van den Berg, L., \& Vervliet, B. (2015). The key role of extinction learning in anxiety disorders: Behavioral strategies to enhance exposure-based treatments. Current Opinion in Psychiatry, 29(1), 39-47. doi: 10.1097/YCO.0000000000000220

Purkis, H., \&Lipp, O. (2001). Does affective learning exist in the absence of contingency awareness?. Learning And Motivation, 32(1), 84-99. doi: 10.1006/lmot.2000.1066

Quirk, G. J., \& Mueller, D. (2008). Neural mechanisms of extinction learning and retrieval. Neuropsychopharmacology, 33(1), 56-72. doi: 10.1038/sj.npp.1301555

Rabinak, C. A., Angstadt, M., Lyons, M., Mori, S., Milad, M. R., Liberzon, I., \& Luan Phan, K. (2014). Cannabinoid modulation of prefrontal-limbic activation during fear extinction learning and recall in humans. Neurobiology of Learning and Memory, 113, 125-134. doi: 10.1016/j.nlm.2013.09.009

Rabinak, C. A., Angstadt, M., Sripada, C. S., Abelson, J. L., Liberzon, I., Milad, M. R., \& Phan, K. L. (2013). Cannabinoid facilitation of fear extinction memory recall in humans. Neuropharmacology, 64, 396-402. doi: 10.1016/j.neuropharm.2012.06.063

Ressler, K.J., Rothbaum, B.O., Tannenbaum, L., Anderson, P., Graap, K., Zimand, E., ... Davis, M. (2004). Cognitive enhancers as adjuncts to psychotherapy: Use of Dcycloserine in phobic individuals to facilitate extinction of fear. Archives of General Psychiatry, 61(11), 1136-1144. doi: 10.1001/archpsyc.61.11.1136

Rodrigues, H., Figueira, I., Lopes, A., Goncalves, R., Mendlowicz, M. V., Coutinho, E. S. F., 
\& Ventura, P. (2014). Does d-cycloserine enhance exposure therapy for anxiety disorders in humans? A meta-analysis. PLoS ONE, 9(7), e93519. doi: 10.1371/journal.pone.0093519

Schiller, D., Monfils, M. H., Raio, C. M., Johnson, D. C., Ledoux, J. E., \& Phelps, E. A. (2010). Preventing the return of fear in humans using reconsolidation update mechanisms. Nature, 463(7277), 49-53. doi: 10.1038/nature08637

Sevenster, D., Beckers, T., \& Kindt, M. (2014). Fear conditioning of SCR but not the startle reflex requires conscious discrimination of threat and safety. Frontiers in Behavioral Neuroscience, 8, 32. doi: 10.3389/fnbeh.2014.00032

Sheehan, D. V., Lecrubier, Y., Sheehan, K. H., Amorim, P., Janavs, J., Weiller, E., ... Dunbar, G. C. (1998). The Mini-International Neuropsychiatric Interview (M.I.N.I.): The development and validation of a structured diagnostic psychiatric interview for DSM-IV and ICD-10. Journal of Clinical Psychiatry, 59(20), 22-33. doi: 10.1016/S0924-9338(99)80239-9

Singewald, N., Schmuckermair, C., Whittle, N., Holmes, A., \& Ressler, K. J. (2015). Pharmacology of cognitive enhancers for exposure-based therapy of fear, anxiety and trauma-related disorders. Pharmacology and Therapeutics, 149, 150-190.doi 10.1016/j.pharmthera.2014.12.004

Szymanski, J., \& O’Donohue, W. (1995). Fear of spiders questionnaire. Journal of Behavior Therapy and Experimental Psychiatry, 26(1), 31-34. doi: 10.1016/0005-7916(94)00072$\mathrm{T}$

Tsao, J. C., \& Craske, M. G. (2000). Timing of treatment and return of fear: Effects of massed, uniform-, and expanding-spaced exposure schedules. Behavior Therapy, 31(3), 479-497.doi: 10.1016/S0005-7894(00)80026-X

VanElzakker, M. B., Kathryn Dahlgren, M., Caroline Davis, F., Dubois, S., \& Shin, L. M. 
(2014). From Pavlov to PTSD: The extinction of conditioned fear in rodents, humans, and anxiety disorders. Neurobiology of Learning and Memory, 113, 3-18. doi: 10.1016/j.nlm.2013.11.014

Vasey, M. W., Harbaugh, C. N., Buffington, A. G., Jones, C. R., \& Fazio, R. H. (2012). Predicting return of fear following exposure therapy with an implicit measure of attitudes. Behaviour Research and Therapy, 50(12), 767-774. doi: 10.1016/j.brat.2012.08.007

Vervliet, B., \& Raes, F. (2013). Criteria of validity in experimental psychopathology: application to models of anxiety and depression. Psychological Medicine, 43(11), 22412244. doi: $10.1017 / S 0033291712002267$

Waters, A. M., \& Pine, D. S. (2016). Evaluating differences in Pavlovian fear acquisition and extinction as predictors of outcome from cognitive behavioural therapy for anxious children. Journal of Child Psychology and Psychiatry and Allied Disciplines, 57(7), 869-876. doi: 10.1111/jcpp.12522 


\section{AUTHOR NOTES}

\section{Financial support}

This work was supported by an ANPIR grant to E. F. (grant number BA-3/2016); a KU Leuven program funding grant (grant number PF/10/005) and FP7 Marie Curie International Outgoing Fellowship (grant number 627743) to B. V.; PROMOSAM Investigación en procesos, mecanismos y tratamientos psicológicos para la promoción de la salud mental grant to M. T-F. (grant number PSI2014-56303-RED); Carlos III Health Institute/FEDER grant to M. A. F. (grant number PI16/00144).

\section{Acknowledgments}

We thank Mohammed R. Milad, Ph.D., for providing the stimuli used in the present study and for his general advice on implementing the paradigm in our laboratory.

\section{Conflict of interests}

None. 


\section{DOES FEAR EXTINCTION IN THE LABORATORY PREDICT OUTCOMES OF}

EXPOSURE THERAPY? A TREATMENT ANALOG STUDY

Forcadell et al.

\section{SUPPLEMENTARY MATERIALS}

Methods and Results 


\section{METHODS}

\section{Fear learning paradigm}

We adapted the 2-day fear learning paradigm developed by Milad, Orr, Pitman, \& Rauch (2005).

The US (electric shock) had a duration of $100 \mathrm{~ms}$ and was generated by a Grass S48 stimulator, transmitted via a constant current unit, and delivered to the volar surface of the non-dominant forearm using a bipolar bar electrode. It was adjusted for each participant to be 'definitely annoying but not painful'. Participants were told that they would see images of two different rooms during the experimental task and that they may or may not be shocked. They were also told that, in case they were shocked, it would be at the end of the presentation of the images.

Before the experimental task, participants received four practice trials (in which the two CSs and the two contexts were combined). Then six startle probes were presented in order to further habituate responding.

The procedure on the first part of day 2 was the same as on day 1, with the following exceptions: participants were told that the shock intensity selected the day before would be used; they were reminded of the instructions; and they were told that they had to use their memory of what they had learned the previous day to predict the occurrence of the US (shock). They did not receive any practice trials, and 10 habituation startle probes were presented before the extinction recall phase.

Trial order was randomized across participants in blocks of nine trials (three of each type), with the restriction that no more than two trials of the same type occurred consecutively. Assignment of the rooms to the conditioning and the extinction contexts, and of the $\mathrm{CS}+$ and the $\mathrm{CS}-$, was counterbalanced across participants. 


\section{Recording and quantification (fear learning paradigm) \\ Skin conductance response (SCR)}

Physiological measures were recorded using a Biopac 150 polygraph (BiopacSystems, Inc).

SCR was recorded at the distal phalanges of the index and the middle fingers of the nondominant hand using two $\mathrm{Ag}-\mathrm{AgCl}$ electrodes filled with electrolyte.

\section{Fear-potentiated startle (FPS)}

The startle blink was measured by recording the electromyographic activity (EMG) of the orbicularis oculi, using two $0.5 \mathrm{~cm} \mathrm{Ag-AgCl}$ surface electrodes. The raw EMG signal was sampled at a rate of $2000 \mathrm{~Hz}$, filtered (analogue 50-Hz notch filter; and digital infiniteimpulse-response, 28 to $500 \mathrm{~Hz}$, band-pass filter), and rectified and smoothed offline (10-ms moving window average).

\section{Fear extinction indices}

The calculation of the fear extinction indices is shown in Table S1.

\section{Table S1. Calculation of fear extinction indices.}

\begin{tabular}{l|c|c}
\hline \multicolumn{2}{c}{ EXTINCTION LEARNING } & Reference \\
\hline US expectancies & $100-([\operatorname{mean}[(\mathrm{CS}+)-(\mathrm{CS}-)]$ during the last two trials of early extinction & Based on Pineles et al. (2016) \\
SCR & learning] / [mean[(CS+) - (CS-)] during first two trials of early extinction & \\
\hline learning $] * 100)$. & Based on Rabinak et al. (2013) \\
SCR & EXTINCTION RECALL & \\
FPS & Mean $[(\mathrm{CS}+)-(\mathrm{CS}-)]$ during first two trials. & \\
\hline
\end{tabular}

CS+: Conditioned stimulus associated with the unconditioned stimulus during conditioning; CS-, Conditioned stimulus not associated with the unconditioned stimulus; US, Unconditioned stimulus; SCR, Skin Conductance Response; FPS, Fear-Potentiated startle. 


\section{Exposure therapy analog}

During exposure therapy analog (ETA), interleaved phobic and neutral images were displayed on a computer monitor in front of the participant. Selection of the phobic and neutral images was made by two pilot participants who were shown a pre-selected set of 30 pictures of spiders, which rated on a scale from 0 (no fear or anxiety) to 10 (severe fear or anxiety). In this study we used fifteen phobic images eliciting medium/strong fear/anxiety (i.e. scores between 5 and 8 ) and two neutral images (of a pen and a fork) eliciting no fear/anxiety (scores between 0 and 2).

The VAS ratings (ranging from 0 (no fear/anxiety) to 10 (high fear/anxiety)) were averaged for each picture, yielding a total of 20 VAS scores for the phobic and 20 VAS scores for the neutral stimuli.

\section{RESULTS EXCLUDING PARTICIPANTS WITHOUT SUCCESSFUL FEAR CONDITIONING AND EXTINCTION LEARNING}

Our criteria for establishing successful fear conditioning were based on the work of Schiller, Raio, \& Phelps (2012): the differential SCR to the CS+ and CS- by the end of the conditioning phase (mean of second half of the conditioning trials) had to be in the right direction (i.e. CS+ $>$ CS-) and $>0.1 \mu$ for SCR, $>1 \mu \mathrm{V}$ for FPS or $>1$ point for $\mathrm{US}$ expectancies. Similarly, the criteria for establishing successful extinction learning were: differential SCR to the CS+ and CS- by the end of the late extinction learning phase (last trial) had to be $\leq 0.1 \mu$ s for SCR, $\leq 1 \mu \mathrm{V}$ for FPS or $\leq 1$ for US expectancies. For indices calculated as a percentage, extreme values (i.e. $>150 \%$ or $<-150 \%$ ) were excluded. 


\section{Fear learning paradigm results}

\section{Extinction learning}

For SCR and FPS and for the whole sample, we found evidence of successful extinction learning (i.e. similar response to the CS+ and CS- in the last block of extinction), as shown by a non-significant CS type main effect and a non-significant CS type $\times$ Block interaction ( $p$ s > .284). Analyses of US expectancies for the whole sample revealed a main effect of CS type $\left(F(1,47)=7.16, p=.010, \eta_{p}^{2}=.132\right)$ but a non-significant CS type $\times$ Block interaction $(p=.096)$.

\section{Extinction recall}

For FPS and for the whole sample, we found evidence of successful extinction recall (i.e. similar response to the CS+ and CS- in the extinction context during the first block of extinction recall), as shown by a non-significant CS type main effect and a non-significant CS type $\times$ Block interaction $(p s>.372)$. For US expectancies and SCR, we found no evidence of extinction recall for the whole sample [significant CS type $\times$ Block interaction for US expectancies: $F(2,86)=13.90, p<.001, \eta_{p}^{2}=.24$; and for SCR: $F(2,32)=5.31, p<$ $\left..001, \eta_{p}^{2}=.25\right]$. 


\section{Table S2. Alternative fear extinction indices.}

\begin{tabular}{|c|c|}
\hline Extinction learning & Reference \\
\hline Mean SCR [(CS+) - (CS-)] of first two trials - mean [(CS+) - (CS-)] of last two trials during extinction learning & Soeter \& Kindt, 2010 \\
\hline $100-([$ mean SCR during the last four CS+ trials of extinction learning / largest SCR of a CS+ trial during conditioning] $* 100)$ & Rabinak et al., 2014 \\
\hline Mean SCR [(CS+) - (CS-)] of early extinction learning - mean SCR [(CS+) - (CS-)] of last two trials of conditioning & Pineles et al., 2016 \\
\hline Mean SCR [(CS+) - (CS-)] of late extinction learning - mean SCR [(CS+) - (CS-)] of early extinction learning & Pineles et al., 2016 \\
\hline \multicolumn{2}{|l|}{ Extinction recall } \\
\hline $100-([\mathrm{SCR}$ of first CS+ trial during extinction recall / largest SCR of a CS+ trial during conditioning] $* 100)$ & Milad et al., 2005 \\
\hline $100-([$ mean SCR $[(\mathrm{CS}+)-(\mathrm{CS}-)]$ of first two trials of extinction recall / largest SCR [(CS+) - (CS-)] during conditioning] * 100) & Milad et al., 2006 \\
\hline $100-($ mean SCR of first two CS+ trials of extinction recall / largest SCR of a CS+ trial during conditioning] * 100) & Milad et al., 2007 \\
\hline $100-($ mean SCR of first four CS+ trials of extinction recall / largest SCR of a CS+ trial during conditioning] * 100) & Milad et al., 2009 \\
\hline $100-\left(\left[\right.\right.$ mean SCR of first two CS+ trials of extinction recall / mean SCR of the two largest CS+ responses during conditioning] ${ }^{*}$ & Hartley et al., 2011 \\
\hline 100) & \\
\hline Mean SCR [(CS+) - (CS-)] of first five trials during extinction recall & Pineles et al., 2016 \\
\hline Mean SCR [(CS+) - (CS-)] of first five trials during extinction recall - mean SCR [(CS+) - (CS-)] of early extinction learning. & Pineles et al., 2016 \\
\hline
\end{tabular}

CS+, Conditioned stimulus associated with the unconditioned stimulus during the conditioning phase; CS+, Conditioned stimulus never associated with the unconditioned stimulus; US, Unconditioned stimulus; SCR, Skin Conductance Response; FPS, Fear-Potentiated startle. 


\section{SUPPLEMENTARY REFERENCES}

Hartley, C. A., Fischl, B., \& Phelps, E. A. (2011). Brain structure correlates of individual differences in the acquisition and inhibition of conditioned fear. Cerebral Cortex, 21(9), 1954-1962. doi: 10.1093/cercor/bhq253

Milad, M. R., Goldstein, J. M., Orr, S. P., Wedig, M. M., Klibanski, A., Pitman, R. K., \& Rauch, S. L. (2006). Fear conditioning and extinction: influence of sex and menstrual cycle in healthy humans. Behavioral Neuroscience, 120(6), 1196-1203. doi: 10.1037/0735-7044.120.5.1196

Milad, M. R., Orr, S. P., Pitman, R. K., \& Rauch, S. L. (2005). Context modulation of memory for fear extinction in humans. Psychophysiology, 42(4), 456-464. doi: 10.1111/j.1469-8986.2005.00302.x

Milad, M. R., Pitman, R. K., Ellis, C. B., Gold, A. L., Shin, L. M., Lasko, N. B., ... Rauch, S. L. (2009). Neurobiological basis of failure to recall extinction memory in posttraumatic stress disorder. Biological Psychiatry, 66(12), 1075-1082. doi. 10.1016/j.biopsych.2009.06.026

Milad, M. R., Wright, C. I., Orr, S. P., Pitman, R. K., Quirk, G. J., \& Rauch, S. L. (2007). Recall of fear extinction in humans activates the ventromedial prefrontal cortex and hippocampus in concert. Biological Psychiatry, 62(5), 446-454. doi: 10.1016/j.biopsych.2006.10.011

Pineles, S. L., Nillni, Y. I., King, M. W., Patton, S. C., Bauer, M. R., Mostoufi, S. M., ... Orr, S. P. (2016). Extinction retention and the menstrual cycle: Different associations for women with posttraumatic stress disorder. Journal of Abnormal Psychology, 125 (3), 349-355. doi: 10.1037/abn0000138 
Rabinak, C. A., Angstadt, M., Lyons, M., Mori, S., Milad, M. R., Liberzon, I., \& Luan Phan, K. (2014). Cannabinoid modulation of prefrontal-limbic activation during fear extinction learning and recall in humans. Neurobiology of Learning and Memory, 113, 125-134. doi: 10.1016/j.nlm.2013.09.009

Rabinak, C. A., Angstadt, M., Sripada, C. S., Abelson, J. L., Liberzon, I., Milad, M. R., \& Phan, K. L. (2013). Cannabinoid facilitation of fear extinction memory recall in humans. Neuropharmacology, 64, 396-402. doi: 10.1016/j.neuropharm.2012.06.063

Soeter, M., \& Kindt, M. (2010). Dissociating response systems: Erasing fear from memory. Neurobiology of Learning and Memory, 94(1), 30-41. doi: 10.1016/j.nlm.2010.03.004 